This item was submitted to Loughborough's Research Repository by the author.

Items in Figshare are protected by copyright, with all rights reserved, unless otherwise indicated.

\title{
Effect of a self-determination theory-based communication skills training program on physiotherapists' psychological support for their patients with chronic low back pain: a randomized controlled trial
}

\section{PLEASE CITE THE PUBLISHED VERSION}

http://dx.doi.org/10.1016/j.apmr.2014.11.007

\section{PUBLISHER}

(C) Elsevier

\section{VERSION}

AM (Accepted Manuscript)

\section{PUBLISHER STATEMENT}

This work is made available according to the conditions of the Creative Commons Attribution-NonCommercialNoDerivatives 4.0 International (CC BY-NC-ND 4.0) licence. Full details of this licence are available at: https://creativecommons.org/licenses/by-nc-nd/4.0/

\section{LICENCE}

CC BY-NC-ND 4.0

\section{REPOSITORY RECORD}

Murray, Aileen, Amanda M. Hall, Geoffrey C. Williams, Suzanne M. McDonough, Nikos Ntoumanis, lan Taylor, Ben Jackson, James Matthews, Deirdre A. Hurley, and Chris C. Lonsdale. 2014. "Effect of a Selfdetermination Theory-based Communication Skills Training Program on Physiotherapists' Psychological Support for Their Patients with Chronic Low Back Pain: A Randomized Controlled Trial”. Loughborough University. https://hdl.handle.net/2134/17143. 


\section{Accepted Manuscript}

The effect of a self-determination theory-based communication skills training program on physiotherapists' psychological support for their patients with chronic low back pain: A randomized controlled trial

Aileen Murray, MSc, Amanda M. Hall , PhD, Geoffrey C. Williams , MD, PhD, Suzanne M. McDonough, PhD, Nikos Ntoumanis, PhD, lan M. Taylor, PhD, Ben Jackson, PhD, James Matthews, PhD, Deirdre A. Hurley, PhD, Chris Lonsdale, $\mathrm{PhD}$

PII: S0003-9993(14)01270-2

DOI: 10.1016/j.apmr.2014.11.007

Reference: $\quad$ YAPMR 56039

To appear in: ARCHIVES OF PHYSICAL MEDICINE AND REHABILITATION

Received Date: 19 June 2014

Revised Date: 6 November 2014

Accepted Date: 8 November 2014

Please cite this article as: Murray A, Hall AM, Williams GC, McDonough SM, Ntoumanis N, Taylor IM, Jackson B, Matthews J, Hurley DA, Lonsdale C, The effect of a self-determination theory-based communication skills training program on physiotherapists' psychological support for their patients with chronic low back pain: A randomized controlled trial, ARCHIVES OF PHYSICAL MEDICINE AND REHABILITATION (2014), doi: 10.1016/j.apmr.2014.11.007.

This is a PDF file of an unedited manuscript that has been accepted for publication. As a service to our customers we are providing this early version of the manuscript. The manuscript will undergo copyediting, typesetting, and review of the resulting proof before it is published in its final form. Please note that during the production process errors may be discovered which could affect the content, and all legal disclaimers that apply to the journal pertain. 
The effect of a self-determination theory-based communication skills training program on physiotherapists' psychological support for their patients with chronic low back pain: A randomized controlled trial

Authors: Aileen Murray, $\mathrm{MSc}^{1}$, Amanda M. Hall, $\mathrm{PhD}^{1}$, Geoffrey C. Williams, MD, $\mathrm{PhD}^{2}$, Suzanne M. McDonough, $\mathrm{PhD}^{3}$, Nikos Ntoumanis, $\mathrm{PhD}^{4}$, Ian M. Taylor, $\mathrm{PhD}^{5}$, Ben Jackson, $\mathrm{PhD}^{6}$, James Matthews, $\mathrm{PhD}^{1}$, Deirdre A. Hurley, $\mathrm{PhD}^{1}$, Chris Lonsdale, $\mathrm{PhD}^{7}$

${ }^{1}$ UCD School of Public Health, Physiotherapy, and Population Science, Health Sciences Centre, University College Dublin, Belfield, Dublin 4, Ireland

${ }^{2}$ Departments of Medicine, Clinical and Social Sciences in Psychology, Psychiatry, Center of Community Health, University of Rochester, 46 Prince St Suite 3001, Rochester, NY 14607, USA

${ }^{3}$ Centre for Health and Rehabilitation Technologies, School of Health Sciences, University of Ulster, Ulster BT37 0QB, UK

${ }^{4}$ School of Sport and Exercise Sciences, University of Birmingham, Edgbaston, Birmingham B15 2TT, UK

${ }^{5}$ School of Sport, Exercise, and Health Sciences, Loughborough University, Leicestershire, LE11 3TU, UK

${ }^{6}$ School of Sport Science, Exercise and Health, University of Western Australia, Crawley, WA, 6009, Australia.

$\#^{7}$ Institute for Positive Psychology and Education, Australian Catholic University, Locked Bag 2002, Strathfield NSW 2135, T: +61 297014642 or +61-435-087-411.

\# corresponding author.

Acknowledgements:

Aspects of this study were presented at the Low Back Pain Foru, Odense, Denmark, 2012 and the International Congress on Physical Activity and Health, Sydney, Australia, 2012.

This research was funded by a Health Research Award (Ref: HRA_POR/2010/102) from the Health Research Board (Ireland). The authors thank the physiotherapists and patients who volunteered to participate in this study. None of the authors has a relationship, financial or otherwise, that could lead to a conflict of interest.

Clinical Trials Registration Number: ISRCTN63723433 
1 The effect of a self-determination theory-based communication skills training program

2 on physiotherapists' psychological support for their patients with chonic low back pain:

3 A randomized controlled trial

4

5

6

7

8

9

10

11

12

13

14

15

16

17

18

19

20

21

22

23

24

25

26

27

28

29

30

31

32

33

34

35

36

37

38

39

40

41

42

43

44

45

46

47

48

Clinical Trials Registration Number: ISRCTN63723433 


\section{Abstract}

53 Objective: To examine communication skills training effects on physiotherapists' supportive 54 behavior during clinical practice.

55 Design: Randomized trial.

56 Setting: Hospital outpatient physiotherapy clinics in Dublin, Ireland.

57 Participants: 24 physiotherapists and 24 patients with chronic low back pain.

58 Interventions: 2 hospital clinics were randomly assigned to the intervention arm.

59 Physiotherapists $(n=12)$ received 8 hours of communication skills training focused on

60 supporting patients' psychological needs. Physiotherapists $(n=12)$ from 2 other hospital

61 clinics formed a waitlist control arm.

62 Main Outcome Measures: Verbal communication between each physiotherapist and a

63 patient was audio recorded and independent, blinded raters used the the Health Care Climate

64 Questionnaire (HCCQ) to assess physiotherapists' needs support behavior (primary

65 outcome).

66 Results: Independent raters' HCCQ scores favored the intervention arm $(p<.01$, Cohen's $d$ $67=2.27)$.

68 Conclusions: Compared with controls, independent ratings demonstrated that

69 physiotherapists who completed CONNECT were seen to provide greater support for

70 patients' needs in a single assessed session. Long-term maintenance of this supportive

71 behavior should be examined. 
74 Key words: communication; physical therapists; patient compliance; motivation; fidelity 75

76 List of abbreviations:

77

78 HCCQ: Health Care Climate Questionnaire

79 HCP: Health Care Practitioner

80 SDT: Self-Determination Theory

81 CLBP: Chronc Low Back Pain

82 
The CONNECT trial ${ }^{1}$ involves evaluation of a communication skills training program, grounded in self-determination theory (SDT) ${ }^{2}$, designed to enhance physiotherapists' support of their patients' psychological needs. The purpose of the current study was to examine intervention effects on physiotherapists' supportive behavior during clinical practice (i.e., intervention fidelity). Examination of intervention fidelity is an important component of effectiveness trials and knowledge translation into clinical practice ${ }^{3}$, but until recently has received limited empirical attention ${ }^{4,5}$.

According to $\mathrm{SDT}^{2}$, people have basic psychological needs for autonomy (feeling fully volitional or free to engage in an activity), competence (feeling effective and capable) and relatedness (feeling connected to and cared for by others). When a patient's psychological needs are supported, participation in treatment is likely to be more selfdetermined, meaning that it is driven by valued benefits and a willingness to participate, and long-term adherence is more likely than when a paternalistic model of care is adopted ${ }^{6}$. Unfortunately, there is evidence that health care practitioners (HCPs) often adopt this latter model of patient care ${ }^{7,8}$.

SDT-based healthcare interventions are designed to teach HCPs the skills needed to support patients' psychological needs, thereby promoting self-determined motivation and engagement in health-promoting behavior. Empirical support for these relationships has been demonstrated in a recent meta-analysis ${ }^{6}$. Drawing on this evidence, a communication skills training intervention, entitled CONNECT, was designed for physiotherapists working with individuals seeking treatment for chronic low back pain (CLBP). Specifically, 
108 physiotherapists were taught 18 SDT-based strategies to enhance their needs supportive

109 behaviors in clinical practice.

110 intervention on blinded observers' ratings of physiotherapists' needs supportive behavior.

This is the first study to test the effectiveness of a SDT-based intervention for physiotherapists. It was hypothesized that physiotherapists who had completed CONNECT training would exhibit greater needs support compared with physiotherapists who had not completed this training.

\section{Methods}

\section{Design}

This study was a multi-center randomized controlled trial (Trial Registration Number

ISRCTN63723433), comprising a cluster randomized design with intervention and control

\section{Randomization}


132

133

134

135

136

1

2

Physiotherapists from each site volunteered to participate in the study prior to randomization TO the clinic to intervention or control. Randomization of cluster sites (i.e., 4 hospital clinics) to intervention and control arms (1:1) was carried out by an independent researcher using a computer-based algorithm. All 4 clinics were randomly allocated at the same time, and a researcher (CL) contacted each clinic to inform them of their allocation arm.

Patients were informed of the purpose of the study, but were not informed whether or not their physiotherapists' clinic had been allocated to the treatment or control condition.

\section{Participants}

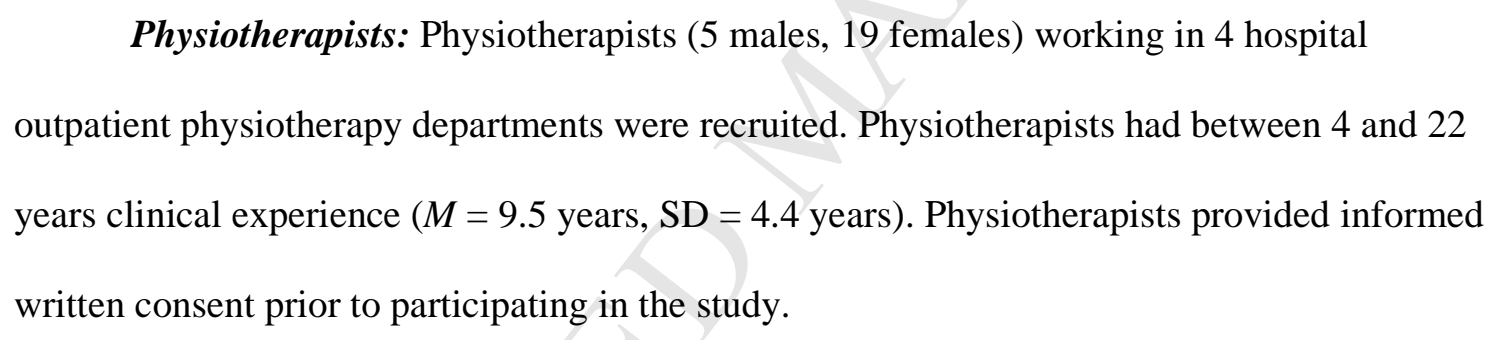

.

48

Patients: Patients referred by a medical practitioner for physiotherapy for CLBP to 1 of the 4 hospitals during the recruitment period were sent an information leaflet outlining the purpose of the study. Informed written consent was gained from 24 eligible participants (6 males, 18 females) prior to baseline assessment. The first author, a registered physiotherapist, screened potential participants via telephone, and then in person prior to their first physiotherapy session, to determine eligibility (see Table 1 for complete inclusion criteria). Exclusion criteria included suspected/confirmed serious spinal pathologies, nerve root involvement, and/or lack of fluency in written/spoken English. 
157

158

159

160

161

162

163

164

165

166

167

168

169

170

171

172

173

174

175

176

177

178

179

180

181

\section{Intervention Overview}

Guided by previous SDT-based interventions with health care providers ${ }^{9-11}, 18$ intervention-specific communication strategies were developed for use in the clinical setting by physiotherapists (see Table 2). To standardize delivery by the workshop leader (CL), and in turn to standardize physiotherapists' implementation of the intervention, the 18 SDT-based strategies were organized into five categories based on the 5A's Framework of Behavior Change ${ }^{12}$ (see Table 2).

\section{Intervention Implementation}

To help standardize the quality of care provided to all patients, physiotherapists from both study arms attended a 1-hour education session. This session reviewed current best evidence-based care for CLBP management, in particular regarding advice for physical activity (e.g. as part of home-based rehabilitation) and exercise prescription ${ }^{13,14}$. Physiotherapists from the intervention arm additionally participated in 8 hours of communication skills training, comprising 2 x 4-hour sessions separated by 1 week (in February 2011). The first training session incorporated an overview of the main SDT concepts, and covered strategies for implementing the communication skills during physiotherapy practice. Video recordings of simulated initial treatment sessions were shown. These vignettes first depicted a physiotherapist displaying controlling communication styles, which were then contrasted with depictions of needs supportive communication behaviors. Active role play and group discussion were also employed. At the end of the session, each 
182

183

184

185

186

187

188

189

190

191

192

193

physiotherapist recorded 2 or 3 goals for strategy implementation during their treatment sessions in the upcoming week, along with likely obstacles and anticipated solutions.

Physiotherapists were provided with choices regarding these goals; they were advised to choose strategies that they believed required most improvement or would have the most benefit for their patients.

The second training block consisted of group discussion regarding the facilitators and barriers to implementing the communication strategies during the previous week. Further simulated video recordings of follow-up physiotherapy sessions with a controlling versus needs supportive communication style were shown, followed by group discussion between the physiotherapists and workshop leader. At the end of the session, physiotherapists revised and set new goals regarding their implementation of the SDT-based strategies over the next 4 weeks. For example, one physiotherapist set a goal to help her CLBP patients set 'SMART' (simple, measureable, achieveable, recorded, and time-based) goals regarding their homebased rehabilitation exercises, and another set a goal to replace a common controlling phrase (“I want you to do this for me, ok?") with a more needs supportive suggestion ("If you do this, you'll give yourself the best chance for improvement"). As in the first session, physiotherapists were advised to choose goals related to strategies they believed required most improvement or would have the most benefit for their patients.

\footnotetext{
At 4 and 10 weeks following the second workshop, the workshop leader sent individualized emails to physiotherapists in the intervention arm. The purpose of these emails was to discuss progress towards the attainment of the implementation goals (examples provided earlier), and to provide assistance in resolving any problems physiotherapists were encountering when implementing needs-supportive communication in their clinical practice.
} 


\section{Recruitment and training of blinded raters}

209

Three individuals were invited to participate in the study as blinded raters. Inclusion criteria were that raters held a $\mathrm{PhD}$ in psychology and had published research on motivation and physical activity in peer-reviewed journals, in the last 5 years. The raters participated in 2 hours of training delivered by 2 of the authors (AM \& CL), during which they discussed the structure of a physiotherapy session and the principles of SDT-based communication strategies in physiotherapy. They also listened to audio recordings of sample physiotherapy sessions (involving physiotherapists and patients not drawn from this study's sample) and practised using the measurement tools employed in this study.

\section{Patient and physiotherapist characteristics measures}

Physiotherapists: All participating physiotherapists $(n=24)$ completed a baseline

assessment package prior to attending the initial 1-hour workshop. In addition to demographics and educational history, data were collected using The General Causality Orientation Scale $(G C O S)^{15}$ to determine the physiotherapists' dispositional motivational orientation (autonomous, controlling, or impersonal). Previous research suggests that these orientations are related to needs-supportive behavior by practitioners ${ }^{20}$ and, thus, GCOS scores provided a means of detecting potential between-arm differences in therapists prior to training. Physiotherapists also completed The Learning Self-Regulation Questionnaire ${ }^{16}$ to determine their motives for participating in a learning activity. 
Patients: Patients completed a self-report questionnaire before their initial

232

233

234

235

236

237

238

239

240

241

242

physiotherapy session, which assessed demographic and motivation variables as well as CLBP severity and disability ${ }^{1}$. All measures for both physiotherapists and patients are presented in Table 3.

\section{Primary outcome measure - physiotherapists' needs support}

Health Care Climate Questionnaire (HCCQ): Audio recordings were made of intial treatment sessions involving 24 physiotherapists, each with a different patient (i.e., the patient's first visit to the physiotherapist). Using a computer-based algorithm, an independent researcher randomly assigned audio recordings to the 3 raters. Raters each listened to 12 recordings and used the HCCQ to assess physiotherapists' needs supportive communication. Thus, 12 randomly selected recordings were rated by a single rater, while a further 12 were double-rated and inter-rater reliability was assessed. The 6-item HCCQ is designed to measure the extent to which a health care practitioner interacts with his or her patient in a needs-supportive manner, and example items included, "the physiotherapist listened carefully to how the participant wanted to do things" and "the physiotherapist tried to understand how the participant saw things before suggesting how to do things". The scale includes 7-point Likert scales, anchored at $1=$ not true at all, $4=$ somewhat true, $7=$ very true ${ }^{16}$. Previous scores derived from the HCCQ have demonstrated good inter-rater reliability and construct validity ${ }^{17}$.

\section{Blinding}


256

257

258

259

260

261

262

263

264

265

266

267

268

269

270

271

272

273

274

275

276

277

278

279

280

Patients were blinded to treatment allocation. Independent raters were also blinded to treatment allocation and study design. Due to the nature of the intervention, it was not possible to blind the treating physiotherapists. Also, logistical constraints meant that the researcher who administered questionnaires was not blinded.

\section{Sample Size}

The required sample size was calculated using an effect size derived from a metaanalytic estimate of blinded needs support ratings associated with SDT-based training (mean effect of $d=1.4$, range of 0.33 to 1.57$){ }^{18}$. Using $G^{*}$ Power software ${ }^{19}$, the sample size needed to detect this effect for the blinded HCCQ ratings $(\alpha=.05,90 \%$ power) was estimated to be 20 participants, 10 in each arm. To allow for potential problems with data collection (e.g., scheduling problems or audio recording difficulties), we aimed to recruit a sample of 24 physiotherapists, 12 in each arm.

\section{Statistical analysis}

Having computed aggregate scores, skewness and kurtosis estimates were calculated for all variables. Descriptive statistics were computed for all patient and physiotherapist characteristics measures, and independent t-tests were employed to explore differences across the study arms. These tests were important because clients' or subordinates' (e.g., employees who report to a manager or students who are required to follow instructions from a teacher) characteristics can influence the needs support that a practitioner provides ${ }^{20}$. Therefore, clinical differences (e.g. differences in pain scores or functional disability) or motivational differences (e.g., patient motivation for treatment or physiotherapists' motivational 
281

282

283

284

285

286

287 288

289

290

291

292

293

294

295

296

297

298

299

300

301

302

303

304

\section{8}

orientations) across the trial arms could have influenced interactions between patients and physiotherapists.

Primary Analysis: An independent t-test was implemented to assess between-arm differences on blinded raters' HCCQ ratings. An effect size (Cohen's $d$ ) ${ }^{21}$ and a $95 \%$ confidence interval was also calculated. In line with Cohen's recommendations, we interpreted $d$ values of $0.2,0.5$ and 0.8 as small, moderate, and large, respectively.

\section{Results}

once the prespecified sample size had been reach. On average, patients attended their initial appointment and had their interactions with their physiotherapist audio recorded 16.7 weeks $(\mathrm{SD}=6.9$ weeks) after the end of the CONNECT training (i.e., February, 2011). No adverse events were reported.

\section{Patient and Physiotherapist Characteristics}

Patient demographics and CLBP-related variables (e.g., pain-related disability ${ }^{22}$ and health status ${ }^{23}$ ) were similar to previous CLBP research in Irish public hospitals ${ }^{24,25}$. There were no significant $(p>.05)$ or clinically meaningful between-arm differences on any patient or physiotherapist characteristic variables (Table 4).

305 
306

307

308

309

310

311

312

313

314

315

316

317

318

319

320

321

322

323

324

325

326

327

328

329

330

Needs support (HCCQ) scores provided by blinded raters were normally distributed (skewness/kurtosis values in the range -1 to +1 ), supporting the use of independent t-tests. Inter-rater reliability on the 12 double-rated recordings was also acceptable $(\mathrm{ICC}=.79)$. An independent samples $t$-test demonstrated that there was a large between-arm difference in needs support scores $(p<.001, d=2.27,95 \% \mathrm{CI}=1.18-3.21)$, with intervention arm physiotherapists $(M=4.57, S D=0.85)$ rated as significantly more supportive than control arm physiotherapists $(M=2.78, S D=0.72)$.

\section{Discussion}

(1)

To the authors' knowledge, this is the first study to investigate the effect of a SDTbased communication skills intervention on physiotherapists' needs supportive behavior. Analyses indicated that the intervention had a large positive influence on physiotherapists' needs supportive behavior with patients under experimental conditions, thus supporting the main study hypothesis.

Although this is the first study to use an intervention based on SDT principles in a physiotherapy setting, other interventions have been conducted with HCPs treating patients for whom behavior change is a main focus of treatment (e.g., physicians counselling smokers to quit) ${ }^{26}$. A recent meta-analysis included five studies that examined the effect of SDTbased interventions on HCPs' needs supportive behavior ${ }^{18}$. Effect sizes associated with blinded needs support ratings in these studies ranged from $0.33^{27}$ to $1.57^{26}$. One possibility as to why the effect in this study was relatively larger in magnitude is that physiotherapists may be particularly amenable to this type of training and, therefore, implemented the communication strategies more closely to protocol compared with HCPs in other studies. However, it should be noted that the lower bound of the 95\% CI for our effect ( $d=1.18$ to 
331 3.21) falls within the range of effect sizes found in other studies (0.33 to 1.57). Thus, our

332

333

334

335

336

337 seemingly larger effect may be an artifact of chance attributable to our relatively small sample size. Physiotherapists may, in fact, be similar to other HCPs in their capacity to learn and implement needs supportive behavior in clinical practice.

\section{Strengths and Limitations}

It is noteworthy that this study was powered to detect differences in the primary outcome, and that this outcome was collected using a gold-standard method, namely observation by expert assessors who were blinded to treatment allocation ${ }^{28}$. This approach is particularly valuable in order to overcome various biases associated with self- and patientreported data ${ }^{29}$.

A limitation of this study was that physiotherapists' needs support in clinical practice was only assessed at one time-point. Ideally, to determine if the effects of the intervention on needs supportive behaviors persist over time, physiotherapists' behavior should be assessed at various time points ${ }^{5,28}$. Also, investigating the physiotherapists' change in needs support from before to after the communication skills training would have allowed us to more confidently attribute between-arm differences to the intervention effects. To partially address this limitation, we assessed physiotherapists' motivational orientation (General Causality Orientation Scale) as this has been shown to correlate with needs supportive behavior ${ }^{20}$. Baseline scores on this measure across the 2 arms of the trial were similar; however differences in needs support prior to the intervention are still possible.

Another potential limitation of this study relates to the degree to which physiotherapsists implemented the intervention in a standardized fashion. The 5A framework 
was also intended to assist physiotherapists in implementing effective communication in their clinical practive by way of structured approach (that could be modified based on their clinical judgement). In keeping with SDT principles, however, physiotherapists were also provided with choice regarding the specific strategies they felt were most important or required the most improvement. This approach recognizes that physiotherapists all have unique communication skills before arriving at training and a tailored approach is appropriate to maximize the degree to which physiotherapists communicated with their patients in a manner that was consistent with the theory-driven principles and strategies in the training (i.e., standardized implementation of communication skills). Ideally, baseline recordings could be analyzed prior to training by workshop leaders or mentors who could then help guide physiotherapists towards the communication skills that required greatest improvement.

Finally, one must also consider the potential impact of the presence of the dictaphone in the treatment area. Having a recording device nearby may have resulted in physiotherapists in experimental group temporarily displaying the communication skills taught in the workshops. In future, researchers may wish to examine physiotherapists' behavior in a less obtrusive manner and, as noted previously, examine behaviour in multiple sessions over an extended period of time in order to more accurately measure therapists' normal clinical practice.

\section{Future research}

Future research should employ larger samples and investigate the extent to which treatment effects endure over time. Researchers could also investigate the feasibility of incorporating SDT-based communication skills education into undergraduate and postgraduate programs. However, the effect on patient outcomes and the cost effectiveness 
381

382

383

384

385

386

387

388

389

390

391

392

\section{4}

of the intervention should be examined before methods for widespread implementation are developed and employed ${ }^{13}$. Analysis of outcomes from the main CONNECT trial will provide initial evidence in this regard ${ }^{1}$.

\section{Conclusions}

Communication that supports patients' psychological needs can lead to better outcomes, but is often not employed by HCPs. This study indicates that, in a single consultation session, greater needs supportive behavior was evident for HCPs who participated in the CONNECT intervention relative to those in a non-intervention control group. ${ }^{15,22,23,31-36}$ 
394 1. Lonsdale C, Hall A, Williams G, McDonough S, Ntoumanis N, Murray A et al.

395 Communication style and exercise compliance in physiotherapy (CONNECT). A cluster

396 randomized controlled trial to test a theory-based intervention to increase chronic low back

397 pain patients' adherence to physiotherapists' recommendations: study rationale, design, and

398 methods. BMC Musculoskeletal Disorders 2012;13(1):104.

3992 . Ryan RM, Deci EL. Self-determination theory and the facilitation of intrinsic

400

401

402

403

404

405

406

407

408 motivation, social development, and well-being. Am Psychol 2000;55:68-78.

3. Hoffmann TC, Glasziou PP, Boutron I, Milne R, Perera R, Moher D et al. Better reporting of interventions: template for intervention description and replication (TIDieR) checklist and guide. BMJ 2014;348.

4. Lorencatto F, West R, Christopherson C, Michie S. Assessing fidelity of delivery of smoking cessation behavioural support in practice. Implementation Science 2013;8(1):40.

5. Borrelli B. The assessment, monitoring, and enhancement of treatment fidelity in public health clinical trials. Journal of Public Health Dentistry 2011;71:S52-S63.

6. Ng JYY, Ntoumanis N, Thogersen-Ntoumani C, Deci EL, Ryan RM, Duda JL et al. Self-determination theory applied to health contexts. Perspectives on Psychological Science 2012;7(4):325-40.

7. Braddock CH, Edwards KA, Hasenberg NM, Laidley TL, Levinson W. Informed decision making in outpatient practice: Time to get back to basics. JAMA 1999;282(24):2313-20.

8. Holden MA, Nicholls EE, Young J, Hay EM, Foster NE. UK-based physical therapists' attitudes and beliefs regarding exercise and knee osteoarthritis: Findings from a mixed methods study. Arthritis Care Res 2009;61(11):1511-21.

9. Fortier MS, Sweet SN, O'Sullivan TL, Williams GC. A self-determination process model of physical activity adoption in the context of a randomized controlled trial. Psychology of Sport and Exercise 2007;8(5):741-57.

10. Silva MN, Vieira PN, Coutinho SR, Minderico CS, Matos MG, Sardinha LB et al. Using self-determination theory to promote physical activity and weight control: a randomized controlled trial in women. J Behav Med 2010;33(2):110-22.

11. Williams GC, McGregor HA, Sharp D, Levesque C, Kouides RW, Ryan RM et al. Testing a self-determination theory intervention for motivating tobacco cessation: Supporting autonomy and competence in a clinical trial. Health Psychol 2006;25(1):91-101.

12. Whitlock EP, Orleans CT, Pender N, Allan J. Evaluating primary care behavioral counseling interventions - An evidence-based approach. Am J Prev Med 2002;22(4):267-84. 13. Airaksinen O, Brox J, Cedraschi C, Hildebrandt J, Klaber-Moffett J, Kovacs F et al. Chapter 4. European guidelines for the management of chronic nonspecific low back pain. Eur Spine J 2006;15 S2:S192 - 300.

14. Koes BW, Tulder Mv, Lin C-WC, Macedo LG, McAuley J, Maher C. An updated overview of clinical guidelines for the management of non-specific low back pain in primary care. Eur Spine J 2010;19(12):2075-94.

15. Deci EL, Ryan RM. The general causality orientations scale: Self-determination in personality. Journal of Research in Personality 1985;19:109-34.

16. Williams GC, Grow VM, Freedman ZR, Ryan RM, Deci EL. Motivational predictors of weight loss and weight-loss maintenance. J Pers Soc Psychol 1996;70:115-26.

17. Williams GC, Deci EL. Activating patients for smoking cessation through physician autonomy support. Med Care 2001;39(8):813-23.

18. Su YL, Reeve J. A meta-analysis of the effectiveness of intervention programs designed to support autonomy. Educational Psychology Review 2011;23(1):159-88. 
442 19. Erdfelder E, Faul F, Buchner A. GPOWER: A general power analysis program.

443 Behavior Research Methods 1996;28(1):1-11.

444 20. Taylor IM, Ntoumanis N, Standage M. A self-determination theory approach to 445 understanding the antecedents of teachers' motivational strategies in physical education. $\mathbf{J}$ 446 Sport Exerc Psychol 2008;30:75-94.

447 21. Cohen J. Statistical power analysis for the behavioral sciences. 2nd ed. Hillsdale, N.J.: 448 Lawrence Erlbaum; 1988.

449 22. Roland M, Morris R. A study of the natural history of back pain: part I: development

450 of a reliable and sensitive measure of disability in low-back pain. Spine 1983;8(2):141.

451 23. Williams A. EuroQol-a new facility for the measurement of health-related quality of

452 life. Health Policy 1990;16(3):199-208.

453 24. Casserley-Feeney SN, Bury G, Daly L, Hurley DA. Physiotherapy for low back pain:

454 Differences between public and private healthcare sectors in Ireland. Man Ther

$455 \quad 2008 ; 13(5): 441-9$.

456 25. Casserley-Feeney SN, Daly L, Hurley DA. The access randomized clinical trial of

457 public versus private physiotherapy for low back pain. Spine 2012;37(2):85.

458 26. Williams GC, Gagné M, Ryan RM, Deci EL. Facilitating Autonomous Motivation for

459 Smoking Cessation. Health Psychol 2002;21:40-50.

460 27. Williams GC, Cox EM, Kouides R, Deci EL. Presenting the facts about smoking to

461 adolescents: The effects of an autonomy supportive style. Arch Pediatr Adolesc Med

462 1999;153:959-64.

463 28. Bellg AJ, Borrelli B, Resnick B, Hecht J, Minicucci DS, Ory M et al. Enhancing

464 treatment fidelity in health behavior change studies: Best practices and recommendations

465 from the NIH behavior change consortium. Health Psychol 2004;23(5):443-51.

466 29. van de Mortel TF. Faking it: social desirability response bias in self-report research.

467 Aust J Adv Nurs 2008;25(4):40-8.

468 30. Epstein RM, Franks P, Fiscella K, Shields CG, Meldrum SC, Kravitz RL et al.

469 Measuring patient-centered communication in patient-physician consultations: Theoretical

470 and practical issues. Soc Sci Med 2005;61(7):1516-28.

471 31. Black AE, Deci EL. The effects of instructors' autonomy support and students'

472 autonomy motivation on learning organic chemistry: A SDT perspective. Science Education

$473 \quad 1989 ; 84(6): 740-56$.

474 32. Ukoumunne O, Gulliford M, Chinn S, Sterne J, Burney P. Methods for evaluating

475 area-wide and organisation-based interventions in health and health care: a systematic review.

476 Health Technology Assessment (Winchester, England) 1999;3(5).

477 33. Kamper SJ, Ostelo RWJG, Knol DL, Maher CG, de Vet HCW, Hancock MJ. Global

478 Perceived Effect scales provided reliable assessments of health transition in people with

479 musculoskeletal disorders, but ratings are strongly influenced by current status. J Clin

480 Epidemiol 2010;63(7):760-6. e1.

$481 \quad 34 . \quad$ Lovibond S, Lovibond PF. Manual for the depression anxiety stress scales.

482 Psychology Foundation of Australia; 1996.

483 35. Waddell G, Newton M, Henderson I, Somerville D, Main C. A Fear-Avoidance

484 Beliefs Questionnaire (FABQ) and the role of fear-avoidance beliefs in chronic low back pain

485 and disability. Pain 1993;52:157 - 68.

486 36. Levesque CS, Williams GC, Elliot D, Pickering MA, Bodenhamer B, Finley PJ.

487 Validating the theoretical structure of the Treatment Self-Regulation Questionnaire (TSRQ)

488 across three different health behaviors. Health Educ Res 2006;22:691-702. 
$491 \quad$ Figure Legend

492

493 Figure 1: CONSORT Flow Diagram 


\begin{tabular}{|c|c|}
\hline clusion criteria & \\
\hline Age & 18 to 70 years \\
\hline Diagnosis & LBP of mechanical origin with/ without radiation to the lower limb \\
\hline Pain duration & chronic ( $\geq 3$ months) or recurrent ( $\geq 3$ episodes in previous year) \\
\hline Language & English speaking and English literate \\
\hline Contact status & Access to a telephone \\
\hline Exclusion criteria & \\
\hline Pathology & $\begin{array}{l}\text { Suspected or confirmed serious spinal pathology (fracture, } \\
\text { metastatic, inflammatory or infective diseases of the spine, cauda } \\
\text { equina syndrome/widespread neurological disorder). } \\
\text { Nerve root compromise ( } 2 \text { of strength, reflex or sensation affected for } \\
\text { same nerve root) }\end{array}$ \\
\hline Past medical history & Spinal surgery or History of systemic / inflammatory disease \\
\hline Current medical status & Scheduled for major surgery during treatment \\
\hline Treatment status & $\begin{array}{l}\text { Currently or having received treatment for CLBP within previous } 3 \\
\text { months }\end{array}$ \\
\hline Pregnancy & Suspected or confirmed pregnancy \\
\hline Contraindications & $\begin{array}{l}\text { Unstable angina / uncontrolled cardiac dysrhythmias / severe aortic } \\
\text { stenosis / acute systemic infection accompanied by fever No } \\
\text { confounding conditions, such as a neurological disorder or an } \\
\text { intellectual disorder }\end{array}$ \\
\hline
\end{tabular}

Table 1: Patient Inclusion and Exclusion Criteria 


\begin{tabular}{|c|c|c|}
\hline Strategy & Description / Example & $\begin{array}{c}\text { Main Basic } \\
\text { Psychological } \\
\text { Need(s) Targeted }\end{array}$ \\
\hline \multicolumn{3}{|c|}{ ASK } \\
\hline $\begin{array}{l}\text { Using Open } \\
\text { Ended } \\
\text { Questions }\end{array}$ & $\begin{array}{l}\text { "Tell me"/"What"/'How" are useful terms when asking questions } \\
\text { as they allow the patient to elaborate on their story. Example: } \\
\text { "What kind of things are you doing to alleviate the pain at the } \\
\text { moment" }\end{array}$ & Relatedness \\
\hline $\begin{array}{l}\text { Using Single } \\
\text { Questions }\end{array}$ & $\begin{array}{l}\text { Avoid asking multiple questions at one time. Instead, ask one } \\
\text { question and wait for a response before asking a second question. }\end{array}$ & Relatedness \\
\hline Staying Silent & $\begin{array}{l}\text { Allow the patient to complete sentences and finish speaking before } \\
\text { following up with further questions. }\end{array}$ & Relatedness \\
\hline Paraphrasing & $\begin{array}{l}\text { After listening to the patient, summarize your perception of the } \\
\text { main points. Examples: "So what I am hearing is that..." or "It } \\
\text { sounds like ...." }\end{array}$ & Relatedness \\
\hline Empathizing & $\begin{array}{l}\text { Show the patient that you understood the emotions that went along } \\
\text { with the issue being discussed. Examples: "I can see this upsets } \\
\text { you" or "That must be very frustrating". }\end{array}$ & Relatedness \\
\hline $\begin{array}{l}\text { Gauging Patient } \\
\text { Readiness to } \\
\text { accept advice }\end{array}$ & $\begin{array}{l}\text { Ask the patient if he or she is ready to consider advice regarding } \\
\text { activities outside the clinic. Example: "There a number of things } \\
\text { you can do that will help ... would you like to hear a few } \\
\text { suggestions?" }\end{array}$ & Autonomy \\
\hline
\end{tabular}

Catering for

Different

Learning

Preferences

Closing the Loop

Providing a Rationale

Providing Opportunities for Patient Input or Choice
Use a selection of methods (aural, visual, kinesthetic) to educate the patient (during session and take home materials); these methods cater for multiple learning preferences.

Ask patients to paraphrase/demonstrate information that had been provided. Provide corrective feedback as required, and re-test understanding. Example: "To be sure that I was clear could you please tell me, in your own words, your understanding of the ....."

Explain to the patient the rationale behind your advice. Example:

"As we discussed earlier, your back needs support from the muscles around. So, if you can do these exercises you can really provide your back with extra support ..." or "Research shows that $P A$ such as walking is a great way to..."

Ask the patient to provide input or make choices when providing advice. Example: "Getting some physical activity -like going for a walk, riding your bike or swimming - is really good for your back. Is there a type of exercise that you prefer?"
Competence

Competence

Using Support and encourage the patient to accept personal responsibility Autonomy

Autonomy \& Competence 
Supportive Examples: "Here are some things that will help you overcome..."

Phrases Instead or "If you complete these exercises then you'll strengthen your

of Controlling back and it will be less likely to give you pain", instead of "Do this

Language for me" or "You have to..." or "You must...".

\section{AGREE}

Agreed on goals that are Specific, Measurable, Achievable,

Employing

SMART Goal

Setting

Ensuring Active

Patient

Participation in

Goal Setting
Recorded, and Time-based. Example: Earlier you mentioned that you are finding walking hard walking for long periods. For this week we could set a target of 15 minutes walking per day, how many days do you think you could achieve that target in the next week?"

Ask the patient for his/her opinions/comments during goal setting. Take into account patient's subjective history (e.g. family/work commitments). Example: What time of day would suit you best for these exercises?

\section{Competence}

Autonomy \&

Competence

\begin{tabular}{|c|c|c|}
\hline \multicolumn{3}{|c|}{ ASSIST } \\
\hline $\begin{array}{l}\text { Identifying } \\
\text { Barriers and } \\
\text { Obstacles }\end{array}$ & $\begin{array}{l}\text { Discuss at least one likely barrier to following treatment advice. } \\
\text { Example: "Is there anything you can think of that might stop you } \\
\text { from accomplishing your exercise goal?" }\end{array}$ & $\begin{array}{c}\text { Competence \& } \\
\text { Autonomy }\end{array}$ \\
\hline $\begin{array}{l}\text { Identifying } \\
\text { Solutions and } \\
\text { Obstacles }\end{array}$ & $\begin{array}{l}\text { Brainstorm with the patient ways to overcome this barrier (e.g. } \\
\text { 'identifying enablers' and 'cognitive restructuring'). Examples: } \\
\text { "Walking can be a fun and social activity that doesn't seem like } \\
\text { hard work. How would you feel about walking with a } \\
\text { friend/neighbor?" and suggest changing thoughts from "I am too } \\
\text { out of shape to walk to the shop" to "If I take it nice and easy and } \\
\text { remember to breathe, relax and take a rest when I need one, I will } \\
\text { be able to walk to the shop." }\end{array}$ & $\begin{array}{c}\text { Competence \& } \\
\text { Autonomy }\end{array}$ \\
\hline \multicolumn{3}{|c|}{ ARRANGE } \\
\hline $\begin{array}{l}\text { Providing a } \\
\text { Rehabilitation } \\
\text { Diary }\end{array}$ & $\begin{array}{l}\text { Provide the patient with a rehabilitation diary to help him/her keep } \\
\text { track of home-based rehabilitation (e.g., exercise, physical activity). }\end{array}$ & $\begin{array}{c}\text { Competence \& } \\
\text { Autonomy }\end{array}$ \\
\hline Following-Up & $\begin{array}{l}\text { Suggest a specific follow-up appointment, provide guidance } \\
\text { regarding when an appointment should be arranged (e.g., no more } \\
\text { than } 2 \text { weeks later), or inform the patient that no follow-up } \\
\text { appointment is needed. }\end{array}$ & $\begin{array}{c}\text { Relatedness \& } \\
\text { Competence }\end{array}$ \\
\hline $\begin{array}{l}\text { Offering } \\
\text { Contact }\end{array}$ & $\begin{array}{l}\text { Invite the patient to contact you in the event of difficulties or } \\
\text { questions. }\end{array}$ & $\begin{array}{l}\text { Relatedness \& } \\
\text { Competence }\end{array}$ \\
\hline
\end{tabular}

Table 2: Mapping Communication Strategies to the ' $5 \mathrm{~A}$ ' Framework and Self-Determination Theory 


\section{Measure \\ Description}

\section{Physiotherapist}

General Causality

Orientation Scale

$(\mathrm{GCOS})$
This is a 17-item scale that assesses the strength of different global motivational orientations within an individual [15]. Subscales for autonomous, controlled and impersonal personality types are included.

Learning Self-Regulation The questionnaire provides both self-determined and controlling reasons

Questionnaire (LSRQ) for participating in learning experiences and asks individuals to rate on a 7-point Likert scale how true the statement is for them. The questionnaire is divided into two subscales; self-determined regulation and controlled regulation [31].

\section{Patient}

The Modified Core Set of Paitents comeplered the "Bothersomeness Scale", "Interference with Questionnaires in Back Work Scale" and "Satisfaction with Current Symptoms Scale" from the Pain Research "Core Set of Outcomes" [32].

\section{Global Perceived Effect \\ The GPE is an 11-point NRS that assesses the patient's perception of} Scale (GPE) recovery. It is considered to have high face validity and is often used as the reference standard against which other subjective measures are tested when assessing their measurement properties [33].

\footnotetext{
Roland Morris Disability This questionnaire consists of 24 yes/no items regarding the impact of

Questionnaire (RMDQ) back pain on activities of daily living. The RMDQ is used widely in low back pain studies as a standardized measure of activity limitation and
} 
has demonstrated good validity, reliability and responsiveness [22].

EuroQuol-5D

Weighted Index

Depression Anxiety

Stress Scale-21 subscale

(DASS)

The EuroQol is a standardized instrument that provides a simple descriptive profile and a single weighted health index value for health status. It is applicable to a wide range of health conditions for which it has been shown to demonstrate good validity and reliability [23].

The DASS includes a set of three self-report scales designed to measure symptoms of psychological distress including depression, anxiety and stress, the 7-item depression subscale was used in the current study [34].

\section{Physical Activity} pain [35].

\begin{tabular}{ll} 
Perceived Competence & This four-item scale has consistently produced scores with good \\
Scale (PCS) & reliability and validity in relation to a variety of health-related \\
& behaviors, including PA [9] \\
\hline Treatment Self & This 15-item instrument is used to assess self-detemrined and controlled \\
Regulation & motivation towards healthcare treatment, as well as amotivation \\
Questionnaire (TSRQ) & (absencc eof motivation). It has demonstrated good reliability and \\
& validity across diverse health-related behaviors [36].
\end{tabular}

Table 3: Description of Physiotherapist and Patient Characteristics 


\begin{tabular}{|c|c|c|c|}
\hline \multirow[t]{2}{*}{ Characteristics } & Control $(n=12)$ & Experimental $(n=12)$ & $p$ \\
\hline & Mean (SD) & Mean (SD) & \\
\hline \multicolumn{4}{|l|}{ Patients } \\
\hline Age (years) & $47.88(13.05)$ & $46.80(6.30)$ & 0.82 \\
\hline Gender (\% female) & $83.3 \%$ & $75 \%$ & 0.37 \\
\hline Previous LBP (\% YES) & $66.6 \%$ & $75 \%$ & 0.67 \\
\hline Currently employed (\% YES) & $33.3 \%$ & $41.66 \%$ & 0.68 \\
\hline Pain Intensity & $6.50(2.11)$ & $6.75(1.66)$ & 0.75 \\
\hline Pain Bothersomeness & $3.58(1.00)$ & $3.33(.99)$ & 0.54 \\
\hline Pain Activity Interference & $3.33(1.27)$ & $3.83(1.03)$ & 0.26 \\
\hline Symptom Satisfaction & $1.33(0.49)$ & $1.75(1.22)$ & 0.28 \\
\hline Global perception of recovery & $-0.14(2.81)$ & $-0.42(2.68)$ & 0.38 \\
\hline Quality of life & $0.46(0.17)$ & $0.35(0.17)$ & 0.15 \\
\hline Disability & $11.55(4.01)$ & $14.33(3.92)$ & 0.11 \\
\hline Depression & $8.67(6.57)$ & $8.52(8.51)$ & 0.92 \\
\hline Fear-avoidance & $14.92(6.57)$ & $16.25(7.91)$ & 0.66 \\
\hline Perceived competence & $6.6(0.65)$ & $6.88(0.20)$ & 0.18 \\
\hline Self-determined motivation & $-2.42(2.32)$ & $-3.58(3.58)$ & 0.09 \\
\hline \multicolumn{4}{|l|}{ Physiotherapists } \\
\hline Age & $34.92(5.98)$ & $32.67(3.28)$ & 0.27 \\
\hline Experience (years) & $10.17(5.03)$ & $8.83(3.67)$ & 0.47 \\
\hline GCOS (A) & $101.00(6.19)$ & $95.00(8.33)$ & 0.14 \\
\hline GCOS (I) & $45.25(10.34)$ & $39.82(10.75)$ & 0.23 \\
\hline GCOS (C) & $57.00(14.95)$ & $57.91(8.09)$ & 0.86 \\
\hline LSRQ(A) & $6.65(0.43)$ & $6.40(0.77)$ & 0.34 \\
\hline LSRQ (C) & $10.50(3.15)$ & $10.25(3.96)$ & 0.39 \\
\hline
\end{tabular}


Table 4: Patient and Physiotherapist Characteristics. Note: $p \leq 0.05=$ level of significance; GCOS (A) $=$ General Causality Orientation Scale (Autonomous); GCOS (I) = General Causality Orientation Scale (Impersonal); GCOS (C) = General Causality Orientation Scale (Controlling); LSRQ (A) = Learning Self Regulated Questionnaire (Autonomous); LSRQ (C) = Learning Self Regulation Questionnaire (Controlling). 


\section{Cluster Enrollment}

A total of 24 physiotherapists from 4 clinics in Dublin, Ireland were recruited into the study. The clinic was the unit of randomization (cluster $n=4$ )

Prior to allocation of clusters to intervention or control arm, participating physiotherapists $(n=24)$ attended a 1 hour refresher course on the evidence-based management of CLBP and completed a baseline assessment

Clinics allocated to intervention $(\mathrm{n}=2)$

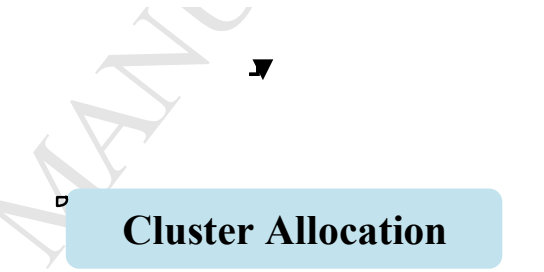

口 Clinics allocated to control $(\mathrm{n}=2)$

口

\section{Intervention}

$2 \times 4 \mathrm{hr}$ communication skills training workshops including an introduction to the principles of Self-Determination Theory and their application to physiotherapy.

\section{Data Collection (Audio Recording of treatment sessions)}

Patient consent was obtained prior to their initial physiotherapy appointment. An audio recording of each participating physiotherapist $(\mathrm{n}=24)$ treating a CLBP patient in clinical practice was collected. 